\title{
RT-LAB based real-time simulation of flywheel energy storage system associated to a variable-speed wind generator
}

\author{
Bensaid Amel $^{1}$, Zebirate Soraya ${ }^{2}$, Chaker Abdelkader ${ }^{3}$ \\ ${ }^{1,2,3}$ SCAMRE Laboratory, Maurice Audin National Polytechnic School of Oran, ENPO, Oran, Algeria \\ ${ }^{2}$ IMSI, University of Oran 2 Mohamed BENAHMED, Oran, Algeria
}

\author{
Article Info \\ Article history: \\ Received Oct 20, 2020 \\ Revised Mar 20, 2021 \\ Accepted Apr 22, 2021

\section{Keywords:} \\ Flywheel energy storage system \\ OP-5600 \\ Opal-RT \\ Power control \\ Real-time simulation \\ RT-LAB \\ Variable speed wind generation
}

\begin{abstract}
This paper presents a new simulator used to distribute and executereal-time simulations: the RT-LAB, developed by Opal-RT Technologies (Montreal, Canada). One of its essential characteristics is the perfect integration with MATLAB/Simulink. The RT-LAB allows the conversion of Simulink models in real time via real-time workshop (RTW) and their execution on one or more processors. In this context, the paper focuses on the RT-LAB real-time simulation as a complement to the Matlab Simulink environment, which has been used to perform the simulation of the Flywheel energy storage system (FESS)-Variable speed wind generation (VSWG) assembly. The purpose of employing a fairly new real-time platform (RT-LAB OP5600) is to reduce the test and prototype time. This application will be executed on each element of our model that was previously developed under MATLAB/Simulink. The real-time simulation results are observed in the workstation.
\end{abstract}

This is an open access article under the CC BY-SA license.

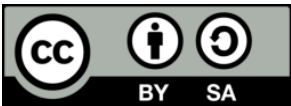

\section{Corresponding Author:}

Bensaid Amel

SCAMRE Laboratory

Maurice Audin National Polytechnic School of Oran

ENPO, Oran, Algeria

Email: bensaid.amel@gmail.com

\section{INTRODUCTION}

In recent days, every researcher wishes to build their models in real-time. Since the mid-20th century, the simulation tools have been used extensively for the conception and development of electrical systems. The improvement of simulation tools has advanced in parallel with the progress of computer technology. These days, computer technology has greatly enhanced its capabilities and has become widely accessible at a constantly declining cost. As a result, simulation tools have also shown dramatic performance gains and consistent decreases in cost. Now the researchers and engineers have the availability of affordable and efficient simulation tools which were earlier too costly, with the exception of the larger manufacturers and utilities. This paper has discussed a particular category of digital simulator known as the real time simulator [1].

The goal of Real-Time Simulation is ensuring that a computing unit works at a pace similar to that of the real physics model. All input treatment, unit computations, and final output are performed in the desired interval of time. Real-time strategies have become time-sensitive and have been utilized for many industry processes such as motors, control power systems, robotics, and games. RT-Lab, created by Opal Laboratory, is most commonly applied due to its versatility and may be used within any approach [2]. The predicators are constructed under the off-line simulink interface of the host PC, while the OP5600 simulation target based on Opal-RT conducts a real-time simulation [3]-[5]. The Real-Time Simulator principally 
consists of a Real-Time delivered simulation package, to run Simulink models on the host computer, as well as the Algorithm Toolkits that are utilized for the fixe time stand simulation of the regulators.

Real-time simulation serves as a useful device for developing control strategies. There are two conditions that may occur based of time needed for simulation deck to conclude the calculation of state output for either time slot:

- if running time, Te of system simulation is less than or equal to the chosen time slot, the simulation is classified as real time

- if Te is larger than its time slot length to one or several time slots, overshoots result so simulation is classified as non-real time. For this last situation, either the time stand size may be enlarged or the system template may be streamlined to execute in real time [6].

This paper will touch on real-time simulation of flywheel energy storage system associated to a variable-speed wind generator, in addition to the Matlab Simulink environment, which was used to perform the simulations mentioned in [7], The popular MATLAB/Simulink was used as an approach to build, edit and visualize graphical models in schematic form. The functional shema designs are the spring from which code may be systematically created, posted, loaded on target CPUs for real-time monitoring. The use of the RTLAB template in Figure 1, existing in the SCAMRE LABORATORY represents many advantages for this kind of applicationssuch us [8]: enables to detect errors at an early stage, ensures coherent time responses, determinism is required when real hardware is connected to the simulation, allows the simulation to lure the real hardware. This paper is organized as follows: The Section 2 presents a brief description about RT-LAB simulator, then how to convert asimulinkmodel to real-time environment in Section 3, Subsequently, we present the REAL-TIME simulation of FESS associated to VSWG under the rt-lab platform. The test results and discussions are described in Section 4 and, finally, the main conclusions are provided in Section 5.

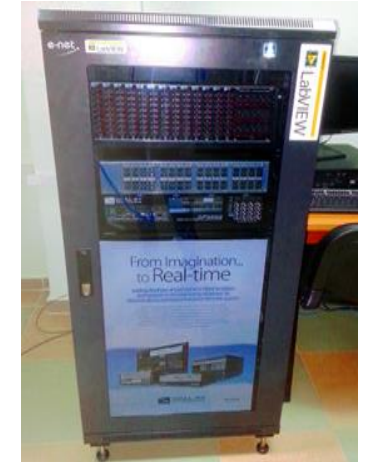

Figure 1. RT-LAB OP5600-Simulator

\section{RT-LAB SIMULATOR}

It is the simulator that we used during the real-time simulation of the studied stockage system. This real-time simulator is available at SCAMRE Laboratory in the National Polytechnic School of Oran, Algeria, is developed by Opal-RT Technologies (Montreal, Canada) [3]. One of its key features is seamless integration with MATLAB/Simulink. It is composed of two parts: Command station (hosts), Computing station (target) as shown in Figure 2 [9], where Table 1 summarizes the RT-LAB specifications used in this paper.

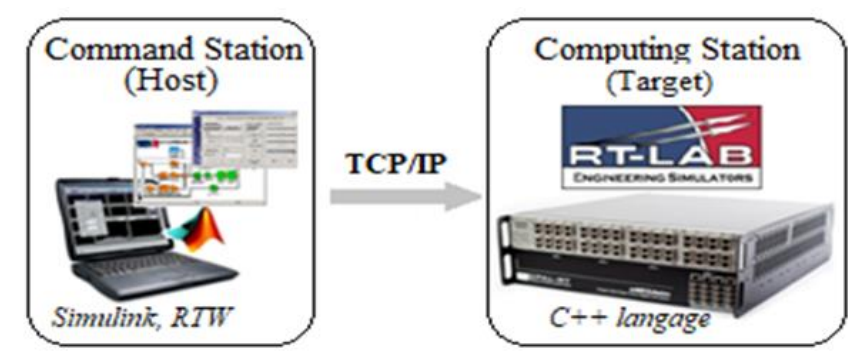

Figure 2. The structure of the RT -LAB simulator 


\begin{tabular}{|c|c|c|c|c|c|c|}
\hline $\begin{array}{c}\text { Simulator } \\
\text { type }\end{array}$ & $\begin{array}{l}\text { RT-Lab } \\
\text { Version }\end{array}$ & $\begin{array}{l}\text { Matlab } \\
\text { Version }\end{array}$ & Processor & Memory & I/O boards & Connectivity \\
\hline OP5600 & 10.7 .8 .521 & R2011b & $\begin{array}{c}2 \text { CPU Intel Xeon } \\
\text { Six-Core } 3.46 \mathrm{GHz} \\
+1 \text { FPGA }\end{array}$ & 12MB Cache & $\begin{array}{l}16 \text { Analog/Digital } \\
\text { channels }\end{array}$ & Ethernet \\
\hline
\end{tabular}

\section{FROM SIMULINK ENVIRONMENT TO REAL-TIME ENVIRONMENT}

The research reported in [7] is focused on the analysis, modelling and non-real-time simulation of the Flywheel Energy Storage System Associated to a Variable-Speed Wind Generator using MATLAB/ Simulink, in the aim to resolve the problem of fluctuating power output. In this work we will describe the modeling and the real-time simulation of the system under study using RT-LAB OP 5600 simulator. One of the strengths points of the OPAL-RT system is the ability to easily convert and use Matlab/Simulink models as real-time simulations. In this section, we will present the different steps required to simulate in real time our model previously built in Simulink.

\subsection{Changing Matlab configuration}

The first step is to modify the configuration of the template with the aim of respect the real-time constraint by choosing a solver for fixed time steps and the single task option [10].

\subsection{Creation of sub-systems}

This step consists of grouping the model into various systems that will be run on different compute nodes. Indeed, each Simulink subsystem must have a name beginning with a specific prefix (Figure 3) [11]:

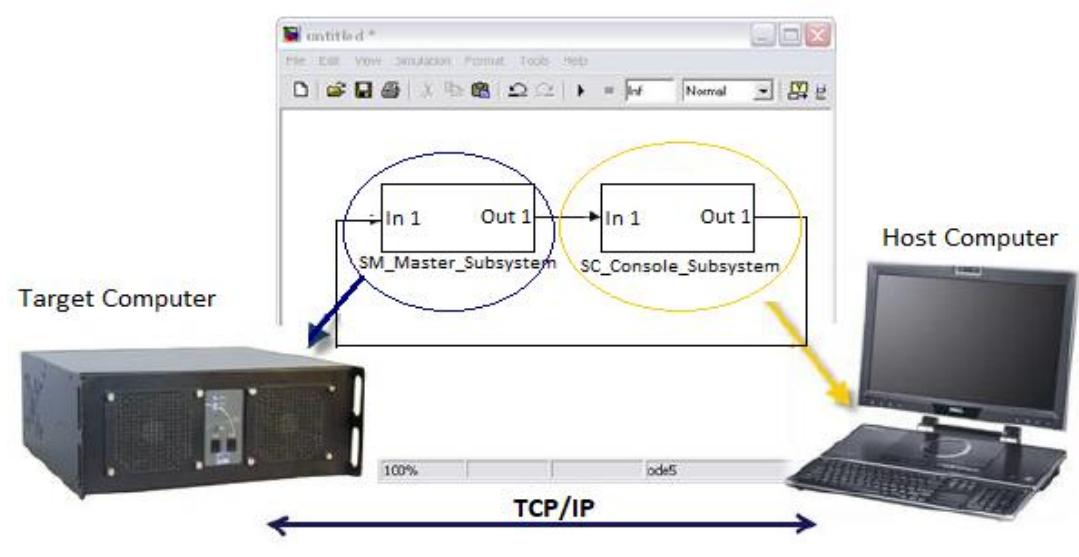

Figure 3. Communication between the console and the computation node

\section{- SC: Console subsystem}

$\mathrm{SC}$ console sub-system is the sub-system running at control station which allows you to interface directly into the system. It includes all the simulink/system build blocs connected to the acquisition and visualization of scopes. The Blocs that are required while or after the real-time model run, should be contained in the bloc $\mathrm{SC}$, when operates in asynchronous mode from the other subsystems. Observe that there can be only one console per model [6].

\section{- SM: Master subsystem}

That is the principal sub-system and each model should have a SM sub-system. All computational components of the model, the mathematical operations, I/O block, and signal generators.

\section{- SS: Slave subsystem}

This subsystem is only necessary if the computational components should be divided among several nodes. All the computational components of the model, the mathematical operations, the I/O block, and signal generators [12]. 


\subsection{Add the OpCommcommunication block(s)}

After grouping the model through console and computing blocks, specific pads named Opcomm have to be included in the subsystems. They are simply traversal blocs which intercept all arriving signals before forwarding them to the computing Bloks of selected subsystem.

\subsection{Execution under RT-LAB}

The last step is to run the model under RT -LAB according to the following steps [9]:

Opening of the model previously developed in Matlab/Simulink (.mdl).

a. Editing the open model for its adjustment and computation in real time.

b. Preparing the original model for code splitting and generating.

c. Assigning subsystems to the physical nodes and activating the eXtreme high-performance mode (XHP).

d. Upload the model by transferring the code via File Transfer Protocol (FTP) to the chosen nodes.

e. Run the model by starting the simulation in real time on all nodes (parallel execution).

\section{REAL-TIME SIMULATION OF FESS ASSOCIATED TO VSWG UNDER THE RT-LAB \\ PLATFORM}

In [7] proves that the FESS shows an attractive way to adjust the production to the consumption. Figure 3 illustrates the real-time model of the FESS-VSWG combination under study. The FESS involved involves a low-speed flywheel and an induction machine, which latter one operates in the weakening flux region, thus allowing operation at rated power [13]-[17]. The VSWG utilized is based on a DFIG wherein its stator is directly linked to the grid and its rotor is linked to the grid through power converters as shown in Figure 4. To study the power transfer between the wind turbine and the grid [18]-[22], we used an independent power control. Thus, two control blocks (FESS control and DFIG control) were available in the device under study. The first one is branched to control the energy storage in the flywheel, the second one is branched to control the active and reactive power exchanged between the grid and DFIG. Both blocks can be controlled separately. A REAL-TIME simulation [23]-[25] has been developed to test the proper functioning of the investigated system, in terms of dynamic response and output power smoothing.

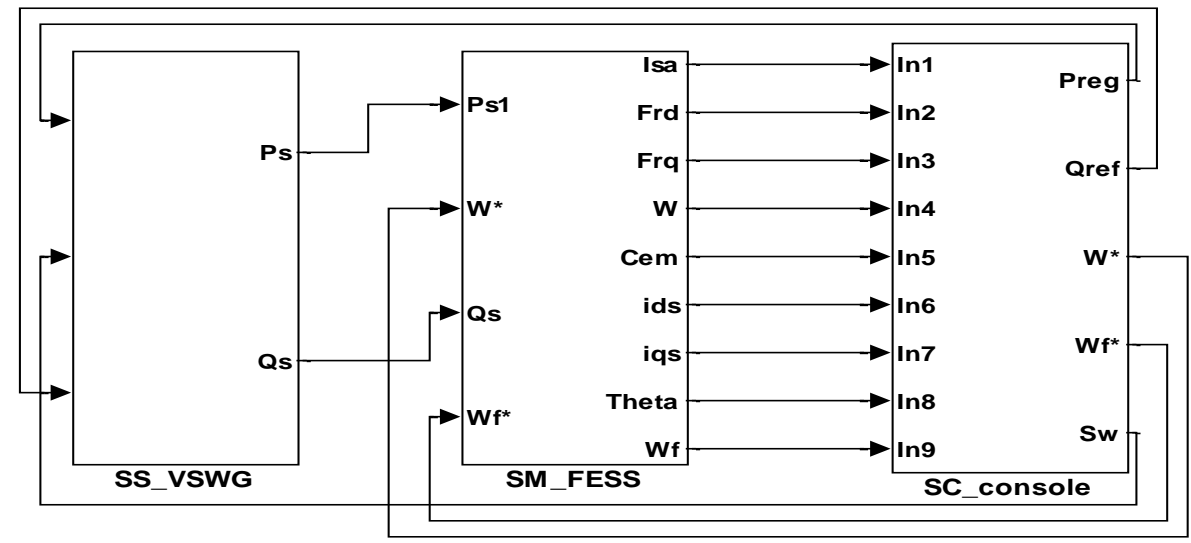

Figure 4. RT-Lab simulation graphic of FESS/VSWG assembly

In Figure 5 presents two subsystems; the first one named "SS_VSWG" contains the simulink model ofthe eolien system. Another named "SM_FESS" contains the simulink model of the storage system, while subsystem named "SC_console" represents the model foronline data acquisition, and Figure 6 also shows the console set which is presented in 2 subsystems 

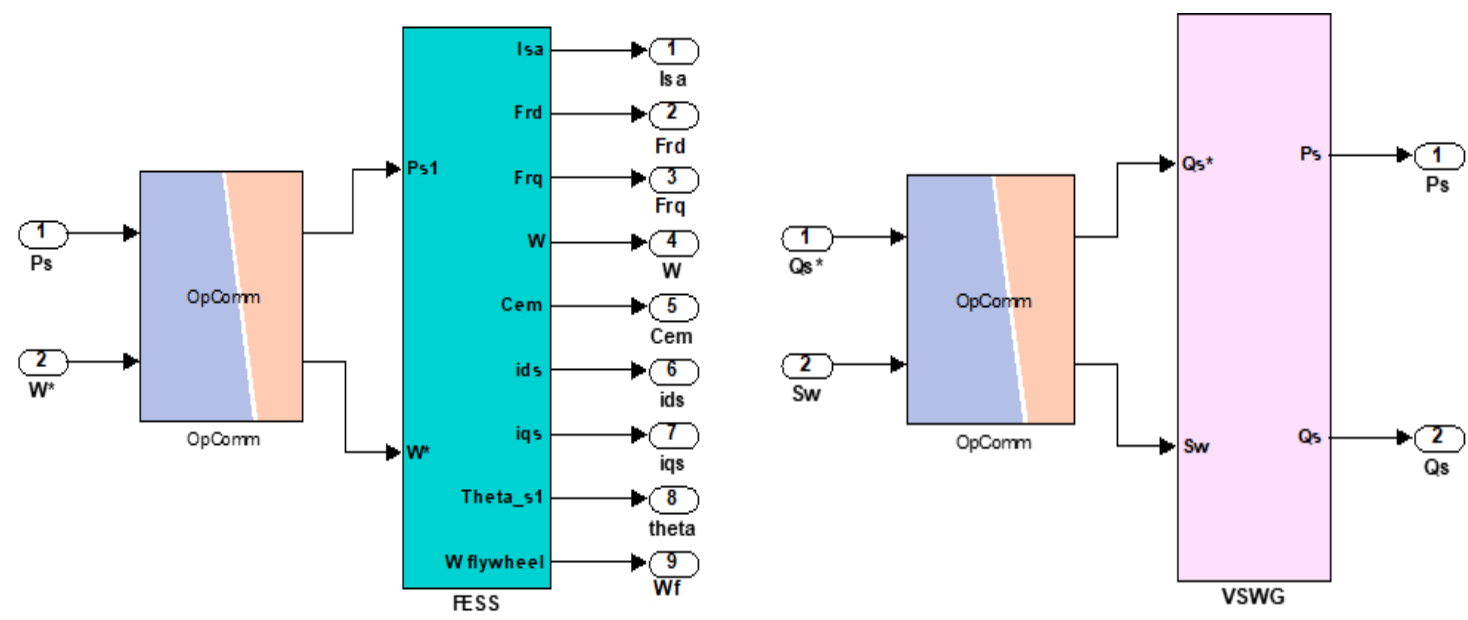

Figure 5. Master and slave subsystems
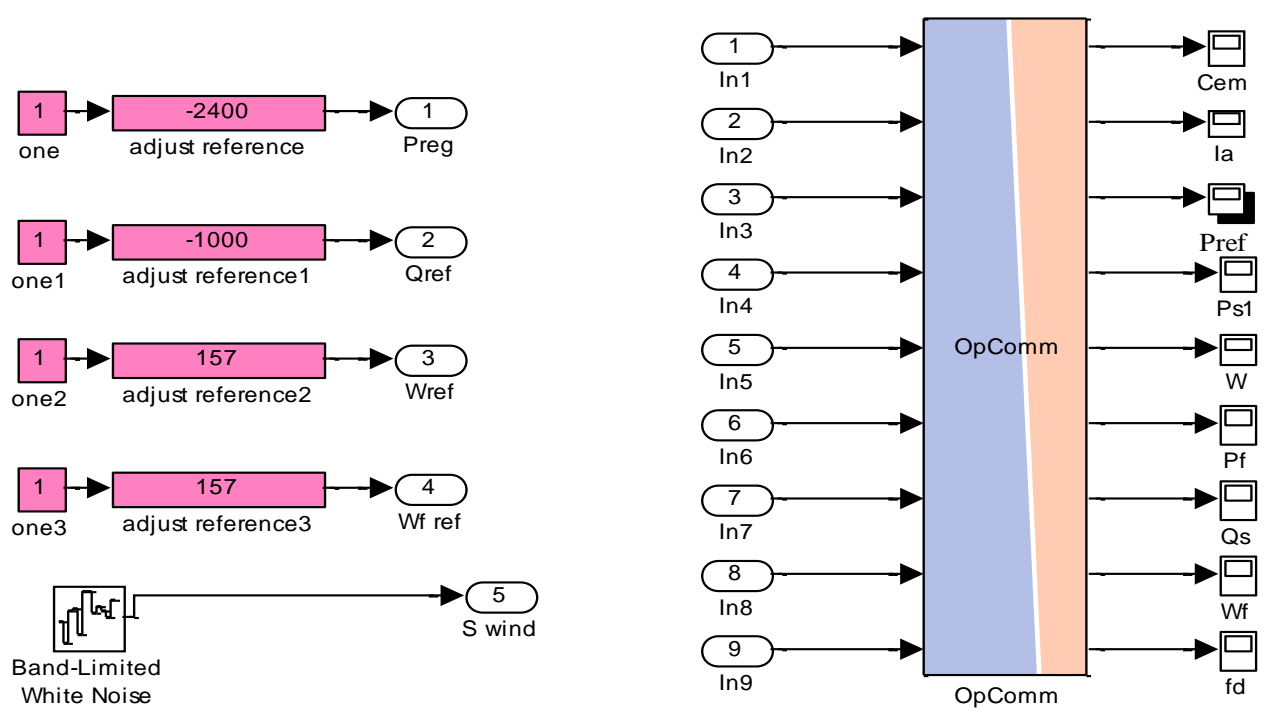

Figure 6. Console subsystem of the set

\section{RESULTS AND ANALYSIS}

The OpWriteFile block is used to save the simulation results in Matlab workspace. The goal is to demonstrate the performance of the FESS on a charge/discharge cycling process utilizing speed control strategy. The simulation of the module in the RT-LAB environment was carried out in fixed steps over a period of 45 secondes while keeping the same parameters of the simulated module in non-real time.

Figures 7 and 8 show the simulation of the indirect field-oriented control of a DFIG-based wind system. These figures demonstrate that our system has satisfactory dynamicwith a null static error.

Figure 9 presents the wind profile, Figure 10 illustrates the delivered power by the wind system to the power grid. It is seen on this figure, that the power grid gets a fluctuating power. The objective of FESS is to adjust this power. Figure 11 corresponds to the storage power flywheel energy storage system. It may be positive or negative. It depends on the wind power and the power load needed. We note that it is positive when the wind power produced is greater than $-2.2 \mathrm{KW}$ (stored energy) and is negative when there is a less power produced compared with that of the load (recovered energy). Figure 12 displays the flywheel speed and its reference. The rotational speed increases when the energy is transferred to the flywheel, and decreases when the flywheel is unloaded. In Figure 13 shows the flux of the IM component corresponding to the response.

The results obtained by RT-LAB are very satisfactory and the dynamics are much improved compared to the results obtained by MATLAB. It is also noted that for a simulation time of 45 seconds, the results of non-real-time simulations lasted 11 minutes, which does not reflect the reality. Whereas, the Real 
Time simulation lasted 45 seconds, which corresponds exactly to the real time. The REAL TIME simulation also gives good performance: High speed response to any setpoint variation; the total absence of overrun; a perfect rejection of perturbation.

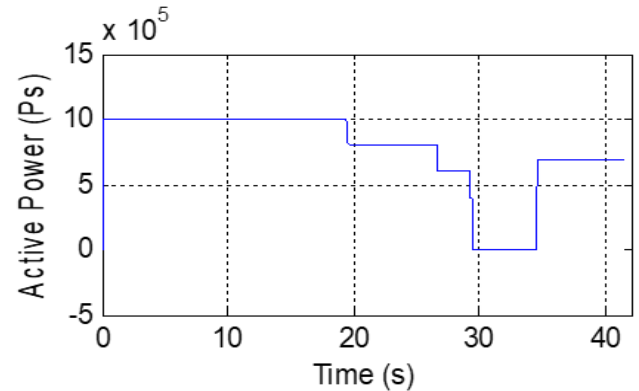

Figure 7. Stator activepower of DFIG

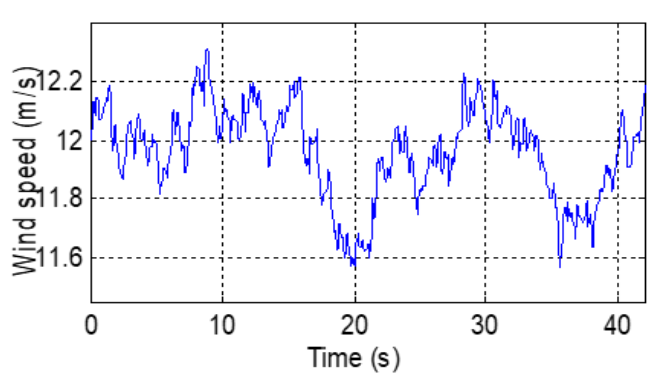

Figure 9. Wind speed

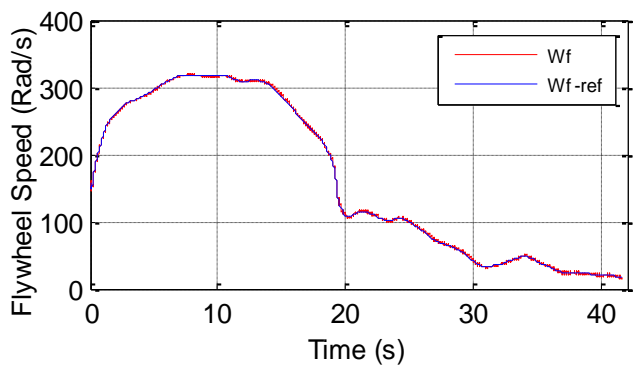

Figure11. Mechanical speed of the flywheel

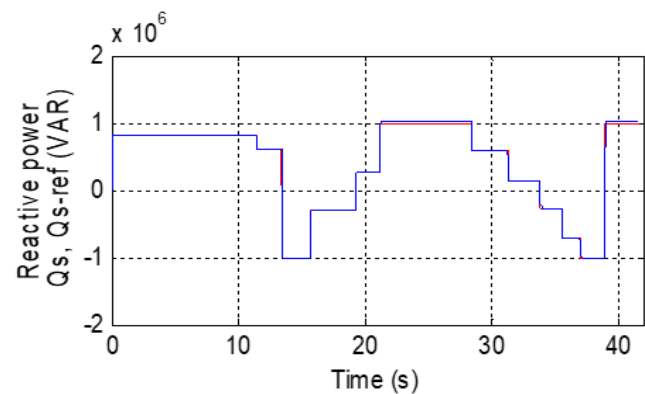

Figure 8. Stator reactive power of DFIG

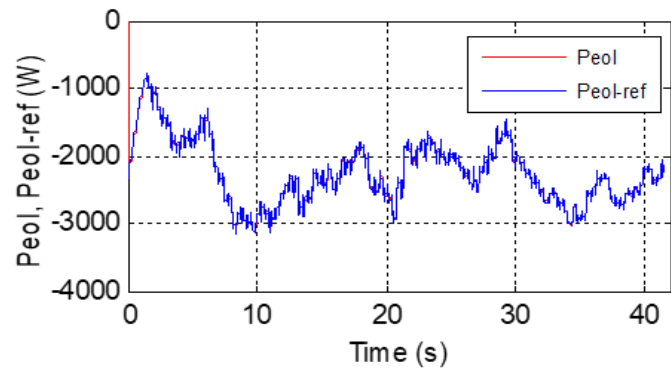

Figure 10. Power generated by the DFIG

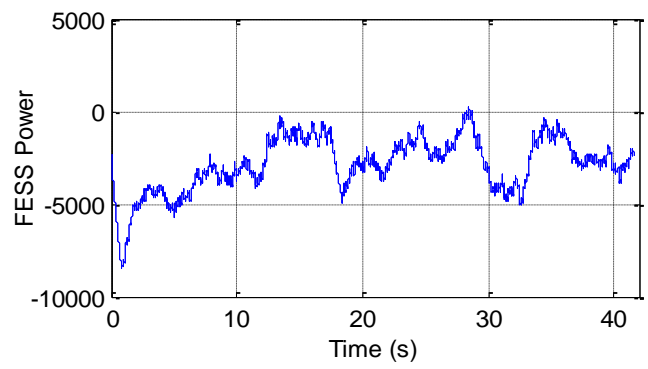

Figure 12. Output active power of the FESS

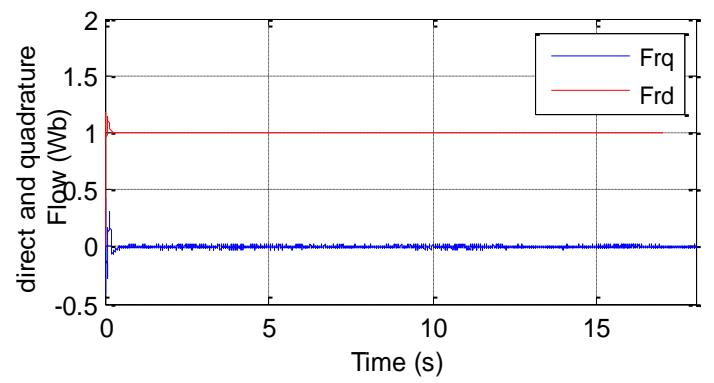

Figure 13. Direct and quadrature component flux of the IM 


\section{CONCLUSION}

It was performed in this work a real-time simulation of the Flywheel energy storage system (FESS) Variable speed wind generation (VSWG) assembly using RT-LAB. Also, this study is an important contribution to rapid control prototyping by using OP5600 OPAL-RT real-time simulator as a core of the RCP system. This application was executed on each element of our model that was previously developed under MATLAB/Simulink. The good control effect is proved by the simulation results. the procedures for charging and discharging are stable and control objectives are achieved. The results obtained by RT-LAB are very satisfactory and the dynamics are much improved compared to the results obtained by MATLAB.

\section{REFERENCES}

[1] S. Mikkiliand and A. K. Panda, "Review of RT-LAB and steps involved for implementation of a simulink model from Matlab to Real-time," Internationl Journal of Emerging Electric Power Systems, vol. 14, no. 6, pp. 641-658, Nov 2013, DOI: 10.1515/ijeeps-2012-0031.

[2] S. M. Krishna and J. L. F. Daya, "MRAS speed estimator with fuzzy and PIstator resistance adaptation for sensorlessinduction motor drives using RT-LAB," Perspectives in Science, vol. 8, pp. 121-126, Apr 2016, DOI: 10.1016/j.pisc.2016.04.013.

[3] W. Li, "RT-LAB for Real-Time Simulation; Applications in Power Electronics," Southern Power Electronics Conference 2017 OPAL-RT Technologies, Dec 2017.

[4] C. Dufour, C. Andrade, and J. Bélanger, "Real-Time Simulation Technologies in Education: a Link to Modern Engineering Methods and Practices," Proceedings of the 11th International Conference on Engineering and Technology Education, Mar 2010.

[5] D. Bian, M. Kuzlu, M. Pipattanasomporn, S. Rahman, and Y. Wu, "Real-time Co-simulation Platform using OPAL-RTand OPNET for Analyzing Smart Grid Performance," 2015 IEEE Power \& Energy Society General Meeting, Jul 2015, DOI: 10.1109/PESGM.2015.7286238.

[6] A. Hamed and A. Hazzab, "Modeling and Real-Time Simulation of Induction Motor Using RT-LAB," International Journal of Power Electronics and Drive System (IJPEDS), vol. 9, no. 4, pp. 1476-1485, Dec 2018, DOI: 10.11591/ijpeds.v9.i4.pp1476-1485.

[7] A. Bensaid, S. Zebirate, and A. Chaker, "Intelligent control of flywheel energy storage system associated with the wind generator for uninterrupted power supply," International Journal of Power Electronics and Drive System (IJPEDS), vol. 11, no. 4, pp. 2062-2072, Dec. 2020, DOI: 10.11591/ijpeds.v11.i4.pp2062-2072.

[8] Leila Ghomri, Mounir Khiat, and Sidahmed. A. Khiat, "Modeling and Real Time simulation of Microgrids in Algerian Sahara area," 2018 IEEE International Energy Conference (ENERGYCON), Jun. 2018, DOI: 10.1109/ENERGYCON.2018.8398785.

[9] A. Idir and M Kidouche1, "RT-lab and dspace: two softwaresfor real time control of induction motors," Revue Roumaine des Sciences Techniques, vol. 59, no. 2 , pp. 205-214, Jan. 2014.

[10] S. K. Singh, B. P. Padhy, S. Chakrabarti, S. N. Singhn, A. Kolwalkar, and S. M. Kelapure, "Development of dynamic test cases in OPAL-RT real-time power system simulator," 2014 Eighteenth National Power Systems Conference (NPSC), Dec. 2014, DOI: 10.1109/NPSC.2014.7103856.

[11] M. Bechar, A. Hazzab, and M. Habbab, "Real-Time Control of AC Machine Drives using RT-LAB Package," Conference: Real-Time Control of AC Machine Drives using RT-LAB Package, Apr. 2018.

[12] R. Umrao, "Load frequency control using fuzzy systems and evolutionary algorithms," Dayalbagh Educational Institute, Feb. 2013.

[13] G. O. Cimuca, C. Saudemont, B. Robyns, and M. M. Radulescu, "Control and performance evaluation of a flywheel energy-storage system associated to a variable-speed wind generator," IEEE Trans. Ind. Electron, vol. 53, no. 4, pp. 1074-1085, Jun. 2006, DOI: 10.1109/TIE.2006.878326.

[14] S. Belfedhal, S. Kouadria, E. M. Berkouk, and Y. Messlem, "Flywheel Energy Storage System with Induction Machine Associated to a Variable-Speed Wind Generator," IEEE, Eighth International Conference and Exhibition on Ecological Vehicles and Renewable Energies (EVER), May 2013, DOI: 10.1109/EVER.2013.6521598.

[15] S. Belfedhal and E. M. Berkouk, "Modeling and control of wind power conversion system with a flywheel energy storage system," International Journal Of Renewable Energy Research (IJRER), vol. 1, no. 3, pp. 43-52, Jun. 2011.

[16] Francisco Díaz-González, A. Sumper, O. Gomis-Bellmunt, and F. D. Bianchi, "Energy management of flywheelbasedenergy storage device for wind power smoothing," Applied Energy, vol. 110, pp. 207-219, Oct. 2013, DOI: 10.1016/j.apenergy.2013.04.029.

[17] F. Zhang, M Tokombayev, and Y Song, "Effective flywheel energy storage (FES) offer strategies for frequency regulation service provision," 2014 Power Systems Computation Conference, Aug. 2014, DOI: 10.1109/PSCC.2014.7038427.

[18] I. Yasmine, E. B.Chakib, and B. Badre, "Improved performance of DFIG-generators for wind turbines variablespeed," International Journal of Power Electronics and Drive System (IJPEDS), vol. 9, no. 4, pp. 1875-1890, Dec. 2018, DOI: 10.11591/ijpeds.v9.i4.pp1875-1890.

[19] F. Senani, A. Rahab, and H. Benalla, "A Complete modeling and control for wind turbine based of a doubly fed induction generator using direct power control," International Journal of Power Electronics and Drive System (IJPEDS), vol.8, no. 4, pp. 1954-1962, Dec. 2017, DOI: 10.11591/ijpeds.v8.i4.pp1954-1962. 
[20] K. Belgacem, A. Mezouar, and N. Essounbouli, "Design and analysis of adaptive sliding mode with exponential reaching law control for double-fed induction generator based wind turbine," International Journal of Power Electronics and Drive System (IJPEDS), vol. 9, no. 4, pp. 1534-1544, Dec. 2018, DOI: 10.11591/ijpeds.v8.i4.pp1954-1962.

[21] I. El Karaoui, M. Maaroufi, and B. Bossoufi, "Robust power control methods for wind turbines using DFIGgenerator," International Journal of Power Electronics and Drive System (IJPEDS), vol. 10, no. 4, pp. 2101-2117, Dec. 2019, DOI: 10.11591/ijpeds.v10.i4.pp2101-2117.

[22] A. Doria-Cerezo, " Modeling, simulation and control of a doubly-fed induction machine controlled by a back-toback converter," PhD Thesis, Universitat Politecnica de Catalunya, 2006.

[23] T. Strasser, "Real-Time Simulation Technologies for PowerSystems Design, Testing, and Analysis," IEEE Power and Energy Technology Systems Journal, vol. 2, no. 2, pp. 63-73, Jun. 2015, DOI: 10.1109/JPETS.2015.2427370.

[24] J. Bélanger, P. Venne, and J.-N. Paquin, “The What, Where and Whyof Real-Time Simulation,” IEEE, pp. 37-49, 2010.

[25] A. Benigni and A. Monti, "A Parallel Approach to Real-Time Simulation of Power Electronics Systems," IEEE Transactions on Power Electronics, vol. 30, no. 9, pp. 5192-5206, Oct. 2014, DOI: 10.1109/TPEL.2014.2361868. 